\title{
THE IMPACT OF BVP IN A TVD BASED PROJECT DELIVERY
}

\author{
Tobias O. Malvik ${ }^{1}$, Bo Terje Kalsaas ${ }^{2}$, Rouzbeh Shabani ${ }^{3}$, and Karl Oscar \\ Sandvik ${ }^{4}$
}

\begin{abstract}
Best Value Procurement (BVP) and Target Value Delivery (TVD) are registered to be increasingly applied in construction, and in some cases, also in the same project. The purpose of our paper is to address these two concepts theoretically and empirically to see if challenges occur when combining BVP and TVD. We deduce the proposition from a theoretical analysis: Best Value Procurement (BVP) is inconsistent with the Target Value Delivery (TVD) approach. We have examined a theoretical-oriented case study of a Norwegian highway construction project. Data was gathered by document analysis, direct observation, and semi-structured interviews. One finding was that BVP did not hinder the client from being a proactive actor and solution enabler in collaboration with the general contractor team. The study shows a lack of alignment of joint project development with a BVP and TVD structure. BVP has proved good results in projects using transactional contracts. However, in projects based on a relational contract, a more direct dialogical procurement approach may be more productive. The paper contributes to the literature by pinpointing conceptual and empirical counterproductive differences when combining BVP and TVD.
\end{abstract}

\section{KEYWORDS}

Best value procurement, Target Value Delivery, contradiction, decision-making.

\section{INTRODUCTION}

Best Value Procurement (BVP) is a procurement system based on the principle that the supplier (the Design-Build contractor and their team) is the expert relative to the client and thereby better suited to identify and handle project risk (Kashiwagi 2011). Target Value Delivery (TVD) emphasises the call for Lean Construction processes in target costing and value engineering. This comprises a management practice that drives the design and construction to deliver customer values within project constraints using costs and a value-driven design process instead of calculating the price after the design is completed, i.e., what value one can get for a given cost (Zimina et al. 2012). Such

1 PhD Candidate, Norwegian University of Science and Technology (NTNU), Trondheim, Norway, +47 98670 354, tobias.o.malvik@ ntnu.no, orcid.org/0000-0002-7588-1899

2 Professor, Dr Ing, University of Agder, Grimstad, Norway, bo.t.kalsaas@uia.no, orcid.org/0000-00034383-1683

3 PhD Candidate, Norwegian University of Science and Technology (NTNU), Trondheim, Norway, rouzbeh.shabani@ntnu.no, orcid.org/0000-0001-8781-7862

$4 \quad$ Independent Researcher, Trondheim, Norway, karl.oscar.sandvik@ gmail.com, orcid.org/0000-0003$\underline{\text { 0882-4306 }}$ 
processes include Integrated Concurrent Engineering (ICE) and consensus decisionmaking with an orientation towards customer value delivery.

BVP and collaborative approaches have been presented as potential means to deal with increasingly large and complex projects in Norway (Malvik et al. 2021). However, there is a lack of a connection between the choice of procurement method and the level of integration it facilitates in the clarification and execution phase. Therefore, this paper aims to study the link between BVP and TVD and see if it is fruitful to combine the concepts.

We first address the method before we outline and discuss the concepts of BVP and TVD. We end the theoretical section by comparing the two concepts as a basis to create a research proposition. Then the case study is presented and discussed.

\section{METHOD}

This paper combines theory with empirical evidence to challenge and verify the applied theoretical informed proposition. A literature review and case study with mostly direct observations, interviews, and document analysis were used to gather information. The observations mainly were direct, but the researcher also had a participating role on some occasions. The case study approach was developed based on the method described by Yin (2018). Different sources lead to triangulation in practices and result in more data reliability (Gray 2013). The literature review aids in familiarising BVP, TVD, procurement procedures, delivery methods, and other related concepts and compliments the interviews from a technical perspective.

In the document analysis, project documents from the case study were reviewed, and essential information project details extracted. A public highway construction project in the design development phase was considered for this study.

An interview guide was designed for the interviews. Five main questions were asked with the guidance of the experienced authors. The interviews were directed by two authors with over 20 years of experience in the construction industry. Follow-up meetings were scheduled with interviewees to address any potential information gaps. The interviews were carried out as semi-structured roleplay exercises by experts in the roles of client project managers and winning contractors. The interviews each took approximately two hours. One of the authors has observed the project for almost one year, being part of its online engineering meetings and ICE sections, where three to five meetings have been observed weekly.

\section{THEORETICAL BACKGROUND}

\section{Best Value Procurement}

BVP was developed by Kashiwagi and his research group at Arizona State University in the period 1991-2010 (Kashiwagi et al. 2012). The concept is claimed to be a paradigm change compared to the traditional Design-Bid-Build model. Kashiwagi also denotes the new approach Performance Information Procurement System (PIPS) regarding the underpinning of theoretical statements. The statements are denoted deductive logic and referred to as "Information Measurement Theory". BVP/PIPS is a licensed technology from Arizona State University. However, it seems like the environment in the Netherlands later to a larger extent address Best Value Approach (BVA) or just Best Value (BV) in 
accordance with Kashiwagi's theory. The difference to BVP is that the execution phase, and not procurement phase, is in center of the approach ${ }^{5}$.

BVP/PIPS was introduced into the Netherlands in 2005 by a large general contractor, Heijmans, and the method was modified to align with European procurement law. Following the introduction to the Netherlands, the methods have become known as BVP, at least in Europe (Kashiwagi et al. 2012).

One statement in the deductive logic is that client decisions increase the risk in construction projects organised as in Design-Bid-Build. In BVP, the basic idea is that the client should minimise risk in the whole project by selecting a vendor to meet this aim. Clients undertake risk reduction by choosing the expert vendor with experience to prevent and minimise risk for both parties. Best value is the best value with the lowest cost measured against the performance in line with the client's project goals. BVP is a process that helps clients choose the expert contractor by feeding necessary information on contractors' performances.

The Norwegian Agency for Public and Financial Management (DFØ) has produced a guide with five phases for BVP (DFØ 2021). The studied case relied on the process described in this guide (Figure 1).

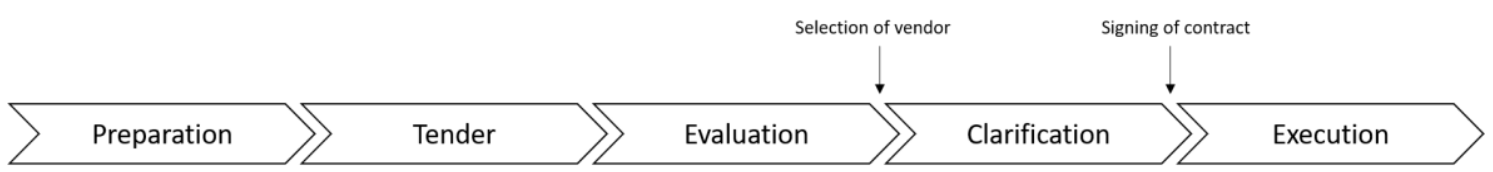

Figure 1: The BVP process, as described by DFØ (2021).

- The Preparation phase includes the presentation of functional requirements, primary goals, and pre-qualification.

- In the Tender phase, the selected vendors are preparing their offer using the required BVP template, and the client is providing the necessary common exchange of information. The template should include text about achievements, a risk assessment, and added value. Project objectives and the allowed cost are decided.

- During the Evaluation phase, all vendors are subject to individual interviews. After ranging the offer, the best vendor is invited to the Clarification phase.

- In the Clarification phase, the best vendor clarifies all risks and describes how to solve the task.

- During project Execution, engineering and construction are carried out using weekly risk reports. The expert vendor controls the project and practices management by risk minimisation.

\section{TARGet VALUE Delivery (TVD)}

The TVD concept has its roots in target costing, which was introduced in the early 1960s by companies in Japan. One of those companies referred by Cooper and Slagmulder (1997) was Toyota. These firms developed two specific cost management techniques to manage the cost of future products: target costing and value engineering.

Target costing deals with the practice of identifying the target cost of a product by subtracting the desired profit margin from the expected selling price; designing the

\footnotetext{
${ }^{5}$ Lecture June $15^{\text {th }}$ 2021, in a DFØ-seminar, by Sander Groebe, Rijkswaterstaat, Ministerie van Infrastructuur en Waterstaat. His lecture was titled Best Value at RWS.
} 
product so that it can be manufactured at the target cost; decomposing the target cost to component level, and using the target cost at this level as the basis for supplier negotiations. Value engineering is a multidisciplinary team effort to explore ways to increase functionality and quality and meet target costs. Functionality is multidimensional and includes both product and service issues. The objective of value engineering is not to minimise product cost but to maximise functionality within any target cost constraint.

Ballard (2011) replaced target costing in construction with target value design (TVD). Until then, target costing had been applied in construction for a considerable time. An example is the Cathedral Hill Hospital project which received considerable attention since it began in 2007 (e.g., Zimina et al. 2012). Later, Ballard (2020) argued that Target Value Delivery should be used instead of Target Value Design. The latter suggests that the mindset is limited to the design phase, while the former includes the whole delivery process. Zimina et al. (2012) argued that TVD applied in construction took the relevant features of target costing to fit the construction context. (Gomes Miron et al. 2015; Ballard 2020) argues that TVD is, like target costing, focused on cost mechanisms but pays more attention to generating value throughout a project.

A fundamental concept of TVD comes from value engineering and the search for alternative components, solutions, and functionality in product development. According to Azari et al. (2014), construction projects are becoming more complex, uncertain, and pushed to move faster. The authors emphasise the importance of relational contracting and Early Contractor Involvement (ECI) to cope with this.

In TVD, the owner defines the Allowable Cost (AC), i.e., how much the owner is willing to pay for the project. Next, the project team determines the Expected Cost (EC) based on the designed Bill of Quantities (BoQ) and related market prices. If the AC is greater or equal to the EC, the project can proceed. Then, the owner/client and contractor agree on a Target Cost (TC) for the project (Johansen et al. 2021). The objective is to drive down the EC during the project by implementing lean construction processes and TVD measures to reach the target cost. TVD projects have an incentive structure to support behaviours in sharing the risks and benefits of cost reduction. It is crucial for the owner and end-users that the final product's value is unaffected by the hunt for reduced work cost. This is why the concept deals with design-to-cost and design to the concrete project goals, which the client sets.

To cope with this, the TVD project approach highlights the importance of trust, collaboration, early involvement of contractors, cross-disciplinary problem-solving, and transparency (Do et al. 2014). Do et al. (2014) indicates from their research that TVD projects achieve 15-20\% lower costs than traditional market bidding projects.

\section{Target Value Delivery (TVD) vs Best Value Procurement (BVP)}

What TVD and BVP have in common is that both approaches have their point of departure in target cost; however, in BVP, the client budget price or maximum price is denoted. Value (for the client) in TVD is the maximum value delivered within the constraint of the target price, not the lowest cost. Value in BVP is conceived in a similar manner but may be more biased to the cost side. Both TVD and BVP measure value related to the specific project goals set by the client.

The differences become visible when we ask how value is achieved. In TVD, value is achieved by collaboration where the client, the designers, and contractors develop and execute the project together. The different experts join forces in mutual processes and joint decision making. In BVP, on the other hand, the expert contractor takes care of the 
execution on behalf of both the client and all the vendors in a transparent environment. Frequent risk reporting is part of this. The vendor takes care of the decisions when they are contracted. During the BVP Tender phase, there is no space for negotiation.

In the case study, the applied procurement method is BVP, and the TVD execution model includes an integrated phase of project development, including the client, designers, and contractors. The execution phase is organised around mutual decision processes and an open book approach. In other words, we deal with something that appears to be a contradiction between the procurement method and the development and execution model.

Following this, we have deduced that Best Value Procurement (BVP) is not consistent with the Target Value Delivery (TVD) approach. The proposition suggests that combining the concepts of BVP and TVD may lead to conflicting results, which will be addressed in the empirical analysis.

\section{CASE STUDY}

Characteristics of the case that has been investigated are presented in Table 1 .

Table 1: Characteristics of the case study.

\begin{tabular}{|c|c|}
\hline Case description & Highway case \\
\hline Scope & $32 \mathrm{~km}$ four-lane highway \\
\hline Procurement method & Best Value Procurement \\
\hline PDM (project development phase) & $\begin{array}{l}\text { Integrated collaboration (inspired by IPD) with } \\
\text { TVD and other LC principles }\end{array}$ \\
\hline PDM (construction phase) & Design-Build with a target price \\
\hline Contract size & $\$ 432$ million \\
\hline Planned construction start-finish & 2021-2025 So \\
\hline Position of the interviewees & $\begin{array}{l}\text { Project managers from the client-side, winning } \\
\text { contractors }\end{array}$ \\
\hline Sources of data & $\begin{array}{c}\text { Five interviews, one year of mainly direct } \\
\text { observation with informal dialogues, document } \\
\text { analysis }\end{array}$ \\
\hline
\end{tabular}

The project uses a collaborative Design-Build contract with a target price, outlined in Table 1. The project delivery method is inspired by Integrated Project Delivery (IPD), though one significant deviation is that the project uses a two-party agreement rather than a multi-party agreement. Otherwise, the PDM is like the IPD approach, and Lean Construction tools, including TVD, are used (Malvik et al. 2020). Figure 2 illustrates the project life cycle and the focus of the study.

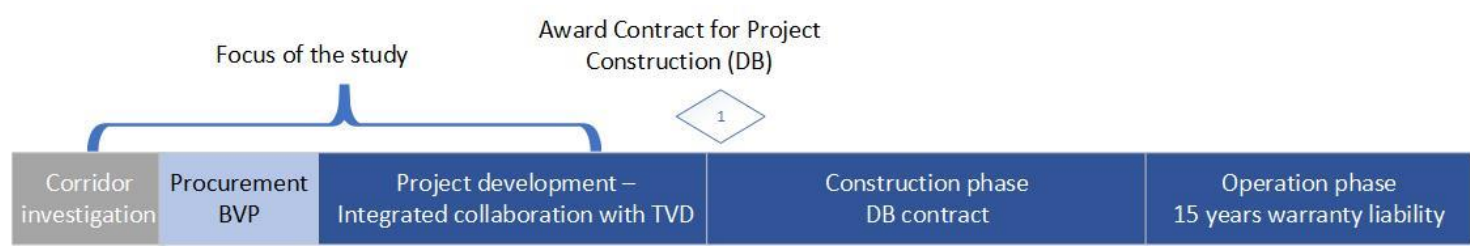

Figure 2: The project life cycle with the study focus highlighted. 
With project collaboration, a client's overall objective is to increase the project value; thus, the client understands TVD as a cornerstone in the collaborative approach. The client has named their Project Delivery Method (PDM) version "Integrated Collaboration." BVP is used as the preferred procurement method for the client. However, data indicate that the client is not considering the $\mathrm{BVP}$ process as more than a procurement procedure, and the project is therefore only modestly embracing the BVP process after the contract award. This means that the execution phase, the fifth phase in the theoretical BVP process (Figure 1), is given little attention in the project execution. Moreover, it is observed that the general contractor's project manager has expressed a strong work identity in the project and possesses an expert role.

In the highway case study examined here, the project development phase for stretches in the south and north parts are currently in the process of re-zonal planning. Detailed designs are being produced in the mid-zone, while early work has already started in defined minor parts. The construction contract for the complete project is expected to be signed in the middle of 2021. It is a current decisive project weight to close the gap between the target cost and bill of quantity (BoQ) based on expected cost.

The project's budget price was developed in three steps. First, the client made an estimate based on a top-down approach and a primary assumption of the road line during a corridor investigation. This estimate gave the client's available project budget. During BVP, all tendering contractors must agree on conducting the project within the client's available funds. The selected contractor confirmed this by signing the contract. This final target estimation was collectively established in the project development phase. If the target price rose above the client budget, the project closed, and the client must start the procurement process again.

The client had established guidelines for their involvement in the design development, which involved facilitating the process and applying a questioning technique. An example of this technique is "Which standard have you applied when engineering the local roads?", where one process revealed unnecessarily high standards for several secondary roads. According to the client, this was caused by a misinterpretation in the existing zoning plan for the highway's long mid-section. Another example is an ICE meeting that failed to include primary functions when selecting an alternative road intersection.

The design and engineering company has the lead in the project development phase and the parallel current detailed design phase for the road project's midsections. Two fulltime design and engineering managers run the processes, except for cost calculations, where the general contractor and a subcontractor on road construction are the executives.

\section{Client involvement}

Data confirms that the client is actively involved in facilitating the processes to improve the workflow in design and engineering. The project has organised the most important decisions of which alternative solutions to select in meetings which are denoted as "ICE" (Integrated Concurrent Engineering), which relate to VDC (Virtual Design and Construction) terminology (Fischer et al. 2017). Concurrent Engineering is, however, a concept that was well-known long before VDC became a buzzword in construction (Love and Gunasekaran 1997). The denoted ICE meetings do not deal with Concurrent Engineering in the studied project but with decision-making on a tactical/operative level. For instance, when deciding on which type of bridge to apply in the crossing of a river.

A "rational" decision-making process is applied (Bazerman and Moore 2009), which can be outlined as 1, define the problem; 2, identify the criteria; 3, weight the criteria; 4 , 
generate alternatives; 5 , rate each alternative on each criterion; 6 , compute the optimal solution. In the studied project, the problem is given. The alignment of the road requires, for example, a road intersection or a bridge. The problem is applied to a developed standardised set of criteria for the decisions in ICE meetings. This reflects the client's goal and value structure on environmental issues, cost, and other factors. Some political considerations related to the later processing of the zonal plan are included in the decision criteria set. Each criterion's weight is standardised in the applied decision model, but the rating is prepared and proposed by multidisciplinary groups to address the different customer values. The alternative options are, for the most part, developed by the designers. The final step of computing the optimal solution takes place in the ICE meeting where more than 30 people from all parties are gathered, and, based on the prepared material, the different values are evaluated. Such a meeting typically lasts for two hours or more, depending on the project complexity.

There are examples from the direct observations where the "best" alternative from the mutual ICE evaluation was later overruled by the clients. This happened during bridge type selection for a river crossing in an environment with significant terrain issues and concerns associated with wildlife and the natural environment. Data indicates that the client's primary reason to change the reached decision was that they believed the expert made the cheapest bridge more complicated than necessary and at a relatively overstated cost. A second example is the selection of an intersection between the planned new highway and another national road. The quality of the preparation of the ICE meeting decision missed out on having the intersection's primary function as one of the decision criteria. Hence, it was a good reason to revise the decision; the client took the lead in the traffic analysis to select a new type of intersection. This decision was later changed again because of the involvement by the local authority, which was unsatisfied by how the second choice dealt with local interests. The third alternative to be launched in the zonal plan is a compromise between the first two.

From the empirical data outlined above, we can see that the general contractor's expert role did not entirely hinder the client's involvement in following client interests on a relatively detailed level. Limited trust can be interpreted as the reason for client intervention in the bridge example above. The two examples addressed are, however, not generalizable in the project.

\section{Cost estimation issues}

We have tried to approach the question of "How deep is the collaboration?". First, it should be noted as a contextual factor that the client was a lean organisation with limited resources to go deep into all issues. The designers developed and submitted BoQ and detailed cost suggestions. The general contractor was responsible for the final cost estimate based on the maturity level in question. The client did not take part in the estimation. We can regard this as an example where the general contractor and their team are considered the experts, as in the BVP framework. An experience from the client perspective, it is difficult to achieve the necessary transparency in this crucial part of the TVD process. Transparency is understood as the communication of issues that gives simple access to decision-relevant information. It is not about keeping information secret. The lack of crucial information does not allow all forces to pull in the same direction to benefit the project.

BoQ cost and output estimation are presented in an aggregated format that is difficult to unpack and identify which elements contribute to its cost. The presentation format is 
not according to the concept of target costing, which distributes the target cost into elements and the cost numbers for subcontractors. Closing the gap between target cost and expected cost addresses the most critical contributing elements of cost and gives a basis for closer inspection and achieve a target cost basis for negotiation with subcontractors. Based on the client's questions, the calculations improved because operational risk and opportunities were identified.

\section{Deviations between project expectations}

Our data indicate that the most significant challenge with BVP is found in the interface between procurement and the collaborative project development phases. The Clarification phase (Figure 1) does not open for negotiation. Following the framework, the general contractor's team explained how they planned to solve the requirements and deliver the project values to the client team. According to a client respondent, the contractor's team expectations were "close, but no cigar" in meeting the client's project expectations. The respondent thought they could clarify more when the contract was signed, but then the project organisation changed pace and proceeded with the development at once.

Moreover, the general contractor team appeared to be locked into the execution model, which they, with earnest effort, had prepared for the clarification phase. A client respondent asked rhetorically in an interview, "expert in what - to build roads or the collaborative processes?" Learning points for the client for future projects of this kind are that they should be more explicit in how they want to have the processes and that BVP is not an acceptable procurement method for projects with a joint project development phase. Negotiations are still necessary at this phase, is the argument.

The client expressed the understanding that "we are the change agent" who should provide the processes. Regarding the change agent role, it is argued that it is not enough to gather highly qualified engineers and believe project development will occur. It is not sufficient for the client to express their wish to apply TVD or Last Planner approaches and expect every contractor to understand the processes. In these self-critical reflections, the Norwegian, and perhaps global markets, are not trained to handle collaborative valuecreating processes, which were, and still are, the ambition in this project. The client addresses the importance of clear responsibility and ownership for the different processes.

\section{DISCUSSION AND CONCLUSION}

There is undoubtedly significant space for improvement in the management of the design and engineering processes regarding applying the principles inspired by Lean Construction. However, it is incredibly challenging to manage these complex and iterative processes in a time-compressed context. Nevertheless, the general impression is that the performance is at least state of the art. This is also indicated by the client, who has expressed that the project development process in the studied project is superior to other highway projects in their portfolio. We will address these processes in more detail in future work.

The general contractor company and its subcontractor participate in the design development regarding buildability and construction preparation. However, based on the ideas underpinning collaborative project development and TVD, we expected a more proactive role from the contractor in the project development phase than was observed.

The project was obliged to apply BVP, and this paper's proposition addresses how this might give unproductive confinement in the execution. In the case study, we found that BVP did not hinder the client in being a proactive actor or a solution enabler in 
collaboration with the general contractor team. However, BVP was not found to enable deep collaboration. Some of the challenges outlined may have been caused by a lack of experience and training by client and contractor in collaborative value-creation processes. That is also the case for the revealed lack of transparency around the BoQ and cost estimation processes which is crucial to produce adequate decision-oriented information for joint decision-making to align with target cost and BoQ cost calculations at different maturity levels as the project development phase proceeds.

The most crucial challenge with BVP for projects with a development phase based on target cost and value engineering is finding the "best" expert since the procurement method does not allow for negotiations. Hence, the clarification phase turns out to be a monologue. From the client's perspective, it was driven by the limited opportunity to clarify and contribute to how the TVD-process should be conducted. BVP's idea of selecting a Design-Build expert based only on their technical skills contrasts with promoting a collaborative dialogue with the client during the execution of a TVD process where soft communication skills would be more productive.

The BVP process is based on the idea that there is an imbalance between client and contractor, where the contractor is considered the expert. In reality, it might be the case that the client is superior to the contractor in some domains of expertise. In the collaborative project approach, the client and contractor are seen as equal partners, allowing for more client involvement. Still, some of the empirical findings highlighted suggest that the contractor, seen as the "expert," felt strong ownership to their "concept" described in the BVP process and was reluctant to consider any concept change.

On the other hand, the client felt that a lack of openness and clarification of the project requirements made them accept decisions that, in their eyes, did not sufficiently fulfil the project requirements. This shows at least two good examples of how the BVP process led to inefficient use of the TVD practice; impatience to start the work immediately after contract-signing resulted in a lack of further clarification to agree on optimal and uniform solutions, and the fact that the contractor is seen as the "expert" in the BVP process did not act in accordance with the collaborative nature of the TVD practice.

BVP has proved good results in projects using transactional contracts where limitations and clarification of responsibility and risk between a DB contractor and the client is crucial (Rivera 2017; Kashiwagi et al. 2019). However, in projects using a relational contract, a more direct dialogical procurement approach might be more productive.

The study is limited in external validity, which was not the main aim, but rather as an example and generalisation in terms of theory. The paper's outcome is a generalisation of a theoretical proposition believed to be true, which, according to Yin (2018), is a justification for conducting a single-case study. The reliability is regarded to be satisfied as it should be quite adequate for other researchers to reach the same result given similar data and theory.

The paper contributes to the literature by pinpointing conceptual and empirical counterproductive differences when combining BVP and TVD, which poorly aligned. In that sense, the proposition and theory are confirmed.

\section{REFERENCES}

Azari, R., Kim, Y.-W., Ballard, G., and Cho, S.-K. "Starting from scratch: a new project delivery paradigm." Proc., Construction Research Congress 2014: Construction in a Global Network, 2276-2285. 
Ballard, G. (2020). "Target Value Delivery." Lean Construction: Core Concepts and New Frontiers, Routledge, 148.

Bazerman, M., and Moore, D. (2009). "Improving decision making." Judgement in managerial decision making, 179-199.

Cooper, R., and Slagmulder, R. (1997). "Factors influencing the target costing process: Lessons from Japanese practice." Citeseer.

DFØ (2021). "Veileder i prestasjonsinnkjøp - Best Value Procurement (BVP)." https://www.anskaffelser.no/verktoy/veiledere/veileder-i-prestasjonsinnkjop-bestvalue-procurement-bvp.

Do, D., Chen, C., Ballard, G., and Tommelein, I. (2014). "Target value design as a method for controlling project cost overruns." International Group for Lean Construction, 22.

Fischer, M., Ashcraft, H. W., Reed, D., and Khanzode, A. (2017). Integrating project delivery, Wiley Online Library.

Gomes Miron, L., Kaushik, A., and Koskela, L. (2015). "Target value design: The challenge of value generation."

Gray, D. E. (2013). Doing research in the real world, Sage.

Johansen, A., Engeb $\varnothing$, A., Torp, O., and Kalsaas, B. T. (2021). "Development of target cost - By the owner or together with Contractors - Target Value Design." Procedia Computer Science, 181, 1171-1178.

Kashiwagi, D. (2011). "Best Value Procurement/Performance Information Procurement System Development." Journal for the Advancement of Performance Information and Value, 3(1), 12-12.

Kashiwagi, D., Kashiwagi, J., Smithwick, J., and Kashiwagi, I. "Changing the paradigm." Proc., Proceedings of the 5th International Public Procurement Conference, 10741095.

Kashiwagi, J., Rivera, A., and Taba, M. (2019). "A Private Organization Utilizes the Best Value Approach on an Enterprise Resource Planning System." Journal for the Advancement of Performance Information and Value, 11(1), 62-79.

Love, P. E., and Gunasekaran, A. (1997). "Concurrent engineering in the construction industry." Concurrent Engineering, 5(2), 155-162.

Malvik, T. O., Engebø, A., Wondimu, P. A., Johansen, A., and Kalsaas, B. T. "Comparing Road Construction Projects Against an IPD Standard." Proc., 28th Annual Conference of the International Group for Lean Construction, IGLC 2020.

Malvik, T. O., Wondimu, P., Kalsaas, B. T., and Johansen, A. (2021). "Various Approaches to Early Contractor Involvement in Relational Contracts." Procedia Computer Science, 181, 1162-1170.

Rivera, A. O. (2017). "Shifting from Management to Leadership: A Procurement Model Adaptation to Project Management." Arizona State University.

Yin, R. K. (2018). Case study research and applications : design and methods, SAGE, Los Angeles.

Zimina, D., Ballard, G., and Pasquire, C. (2012). "Target value design: using collaboration and a lean approach to reduce construction cost." Construction Management and Economics, 30(5), 383-398. 